Article

\title{
New Flavonoid Glycosides from Elsholtzia rugulosa Hemsl.
}

\section{Gaimei She ${ }^{1}$, Zhiqin Guo ${ }^{1}$, Haining $\mathrm{Lv}^{1}$ and Dongmei She ${ }^{2, *}$}

1 School of Chinese Pharmacy, Beijing University of Chinese Medicine, Beijing 100102, China; E-Mails: shegaimei@126.com (G.S.); medicine_guo@163.com (Z.G.); seagullning@163.com (H.L.)

2 The Institute of Plant Protection, Chinese Academy of Agricultural Sciences, Beijing 100049, China

* Author to whom correspondence should be addressed; E-Mails: dongmeishe@yahoo.com.cn; Tel.: +86-10-84738628; Fax: +86-10-84738611.

Received: 21 September 2009; in revised form: 12 October 2009 / Accepted: 20 October 2009 / Published: 20 October 2009

\begin{abstract}
Elsholtzia rugulosa Hemsl. is known in China as a local herbal tea, medicinal herb and honey plant. Chemical examination of E. rugulosa led to the isolation of two new flavonoid glycosides, apigenin 4'-O- $\alpha$-D-glucopyranoside (1) and 5,7,3',4'-tetrahydroxy-5'$C$-prenylflavone-7-O- $\beta$-D-glucopyranoside (2), together with nine known flavonoids. Their structures were elucidated on the basis of spectroscopic evidence.
\end{abstract}

Keywords: Elsholtzia rugulos; flavonoid glycosides; apigenin 4'-O- $\alpha$-D-glucopyranoside; $5,7,3$ ', 4'-tetrahydroxy-5'-C-prenylflavone-7-O- $\beta$-D-glucopyranoside

\section{Introduction}

Elsholtzia rugulosa Hemsl. (Lamicaeae), which is distributed in the Yunnan, Sichuan and Guizhou provinces of China, is known as a local herbal tea, medicinal herb and honey plant [1]. In these regions, the title plant is also widely used by local people in the treatment of colds, headaches, coughs, pharyngitis and fever [2]. Several flavonoids, maltol glycosides and cyanogenic glycosides have been isolated from E. rugulosa [3,4]. The antiviral activities of these flavonoids were also reported [4]. As a part of our systematical investigation of Chinese tea and herbal tea plants, and in the search for biologically active flavonoids from plants sources, a detailed study on ethanol extracts of E. rugulosa was carried out $[5,6,7]$. This led to the isolation of two new flavonoids glycosides, apigenin 4 '-O- $\alpha$-D- 
glucopyranoside (1) and 5,7,3',4'-tetrahydroxy-5'-C-prenylflavone 7-O- $\beta$-D-glucopyranoside (2), together with nine known flavonoids 3-11. Herein, we present the details of this study.

\section{Results and Discussion}

Repeated column chromatography (CC) of the chlorophyll-free fraction of an ethanol extract of $E$. rugulosa on Dianion HP 2MGL, Sephadex LH-20, MCI-gel CHP-20P, and silica gel, resulted in the isolation of 11 compounds, of which nine known flavonoids were identified as luteolin (3) [8] luteolin 7-O- $\beta$-D-glucoside (4) [8], luteolin 3'-O- $\beta$-D-glucuronide-6"-methylester (5) [9], apigenin (6) [10], apigenin 7-O- $\beta$-D-glucoside (7) [11], quercetin 3-O- $\beta$-D-glucuronide-6"-methylester (8) [12], kaempferol (9) [13], 3',4',5,7-tetrahydroxy-8-prenyl-flavone (10) [14] and 7,4-dimethylkaempferol (11) [15], respectively, by direct comparison with authentic samples or comparison of the spectroscopic data with reported literature values. Among them, compounds 7-10 were isolated for the first time from E. rugulosa. The two new compounds were identified as apigenin 4'-O- $\alpha$-Dglucopyranoside (1) and 5,7,3',4'-tetrahydroxy-5'-C-prenylflavone 7-O- $\beta$-D-glucopyranoside (2), and their structures were elucidated as follows.

Compound 1 was obtained as a yellow amorphous powder, and had a molecular formula $\mathrm{C}_{21} \mathrm{H}_{20} \mathrm{O}_{10}$, derived from its negative HR-FAB-MS (m/z $\left.431.1280[\mathrm{M}-\mathrm{H}]^{-}\right)$and ${ }^{13} \mathrm{C}-\mathrm{NMR}$ spectrum. Comparison of the NMR data with those of apigenin [10], and the further 2D-NMR spectral data allow elucidation the structure of compound $\mathbf{1}$ as shown in Figure 1.

Figure 1. Structures of compounds 1 and 2.

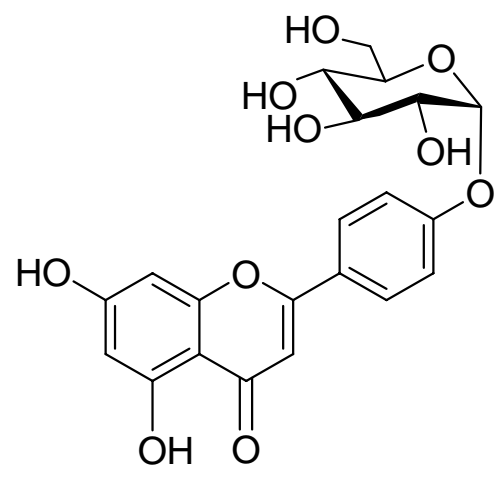

1<smiles>CC(C)=CCc1cc(-c2cc(=O)c3c(O)cc(OC4OC(CO)C(O)C(O)C4O)cc3o2)cc(O)c1O</smiles>

2

The UV spectrum exhibited absorption maxima at $265 \mathrm{~nm}$ (band II) and $331 \mathrm{~nm}$ (band I), that are characteristic flavone skeleton bands. The IR spectrum of $\mathbf{1}$ indicated the presence of hydroxyl $\left(3,376 \mathrm{~cm}^{-1}\right)$ and carbonyl functions $\left(1,640 \mathrm{~cm}^{-1}\right)$. The occurrence of a flavone skeleton in the molecule could be easily deduced from the ${ }^{1} \mathrm{H}-\mathrm{NMR}$ spectrum, in which compound $\mathbf{1}$ showed the signals for an exchangeable proton at $\delta 12.95(1 \mathrm{H}, \mathrm{s}), \mathrm{A}_{2} \mathrm{~B}_{2}$-type aromatic protons at $\delta 7.94\left(\mathrm{~d}, \mathrm{H} 2{ }^{\prime}, 6^{\prime}\right)$ and $6.92(\mathrm{~d}$, H3', 5') on B-ring, two doublets at $\delta 6.43(\mathrm{~d}, \mathrm{H} 6)$ and $6.82(\mathrm{~d}, \mathrm{H} 8)$ on A-ring, together with an olefinic proton at $\delta 6.86(\mathrm{~s}, \mathrm{H} 3)$ on a flavone $\mathrm{C}$-ring. In addition, the ${ }^{1} \mathrm{H}-\mathrm{NMR}$ also exhibited signals due to one $\alpha$-glucopyranosyl unit $[\delta 5.42(\mathrm{~d}, J=3.7 \mathrm{~Hz}, \mathrm{H} 1 ")]$. The $J$ value $(3.7 \mathrm{~Hz})$ of the anomeric proton indicated the $\alpha$-configuration of the glucose moiety [16]. This was supported by the IR spectrum 
showing a strong band at $770,780 \mathrm{~cm}^{-1}$, probably due to one glucosyl unit, and the enzymatic hydrolysis displaying the $R f$ values consistent with those of a standard sample of D-glucose, as well as anomeric carbon signal $\delta 99.9\left(\mathrm{C}\left(1^{\prime}\right)\right)$ of $\alpha$-D-glucosyl group observed, in accord with those of literature values [17,18]. The ${ }^{13} \mathrm{C}$-NMR spectrum of $\mathbf{1}$ exhibited 21 carbons whose aglycon chemical shift were in good agreement with those of apigenin and the sugar moiety chemical shifts were in good agreement with those of $\alpha$-D-glucosyl moiety [18]. The attachment of the glucopyranosyl moiety was deduced to be at C-4' according to glycosylation rule. The conclusion was further confirmed by the HMBC spectrum in which the anomeric proton of the glucopyranosyl moiety at $\delta 5.42$ (d, H1") showed long range correlation with $\mathrm{C}\left(4^{\prime}\right)(\delta$ 161.1). Therefore, the structure of 1 was determined to be apigenin 4'- $O$ - $\alpha$-D-glucopyranoside.

Compound 2 was obtained as a pale yellow amorphous powder. The molecular formula $\mathrm{C}_{26} \mathrm{H}_{28} \mathrm{O}_{11}$ was derived by negative ion HR-FAB-MS (m/z: $\left.515.1913[\mathrm{M}-\mathrm{H}]^{-}\right)$in combination with the presence of 26 carbon signals in its ${ }^{13} \mathrm{C}-\mathrm{NMR}$ spectrum, and the further $2 \mathrm{D}-\mathrm{NMR}$ spectral data allow to elucidate the structure of compound 2 as shown in Figure 1.

The signals at $\delta 6.78(\mathrm{~s}, \mathrm{H} 3)$ ascribable to $\mathrm{C}_{3}$ - proton on a flavone $\mathrm{C}$-ring, and two aromatic proton signals at $\delta 6.61(\mathrm{~d}, \mathrm{H} 6)$ and $6.48(\mathrm{~d}, \mathrm{H} 8)$ due to $\mathrm{H}-6,8$ on A-ring protons, respectively, two broad singlet signals at high field in the aromatic region $\left[\delta 7.40\left(\mathrm{~d}, \mathrm{H} 2^{\prime}\right), 6.95\left(\mathrm{~d}, \mathrm{H} 6^{\prime}\right)\right]$ on B-ring were observed in ${ }^{1} \mathrm{H}-\mathrm{NMR}$ spectrum, which suggested the occurrence in the molecule of a flavone skeleton with a tetra-substituted B-ring. In addition, one glucopyranosyl unit $[\delta(\mathrm{H}) 5.08(\mathrm{~d}, \mathrm{H} 1 "), \delta(\mathrm{C}) 101.9$ $\mathrm{C}(1 ")]$ was evident in the ${ }^{1} \mathrm{H}$ - and ${ }^{13} \mathrm{C}-\mathrm{NMR}$ of 2 . On enzymatic hydrolysis, compound 2 liberated Dglucose and the $J$ value $(8.1 \mathrm{~Hz})$ of the anomeric proton concluded the $\beta$-configuration of the Dglucose moiety. The HMBC correlations of glucosyl H-1" [ $\delta 5.08(\mathrm{~d}, \mathrm{H} 1 ")]$ in 2 with the $\mathrm{C}(7)(\delta 166.7)$ confirmed that the location of glucopyranosyl groups were at C-7 in 2 . These NMR features were resembled to those of luteolin 7-O- $\beta$-D-glucoside (4) [8], except for the existence of an additional set of signals arising from a prenyl group in 2. Characteristic signals of prenyl group were observed at $\delta$ 1.68 (s, H5"'), 1.62 (s, H4"'), 3.62 (m, H1"'), 5.16 (br. t, H2"'), confirming that 2 was a prenylated flavone glycoside [20]. The downfield chemical shift of $\mathrm{C}\left(5^{\prime}\right)$ of $\mathbf{1}$ at $\delta 127.1$ indicated that the additional prenyl group was linked at the $\mathrm{C}\left(5^{\prime}\right)$ position, which was further confirmed by the HMBC correlations of $\mathrm{H} 1^{\prime \prime}$ ( $\left.\delta 3.62\right)$ of prenyl unit with the carbon at $\delta 127.1 \mathrm{C}\left(5^{\prime}\right)$ ) of the flavone glycoside (Figure 2). On the basis of the above evidence, the structure of 2 was elucidated as 5,7,3',4'tetrahydroxy-5'-C-prenylflavone 7-O- $\beta$-D- glucopyranoside.

Figure 2. Key HMBC correlations of 2.

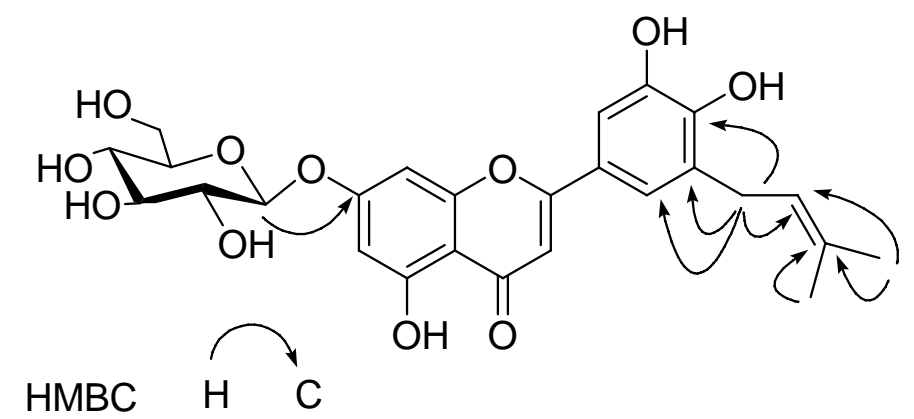




\section{Experimental}

\subsection{General}

Column chromatography (CC) was performed on Dianion HP 2MGL (Mitsuishi Chemical Co.), Sephadex LH-20 (Pharmacia Fine Chemical Co. Ltd.), MCI-gel CHP20P (Mitsubishi Chemical Co.) and silica gel (Qingdao Haiyang Chemical Co.). TLC was carried on silica gel G precoated plates (Qingdao Haiyang Chemical Co.) with $\mathrm{CHCl}_{3}-\mathrm{MeOH}-\mathrm{H}_{2} \mathrm{O}$ (9:1:0.1 or 7:3:0.5). The spots were detected by spraying with $10 \% \mathrm{H}_{2} \mathrm{SO}_{4}$ ethanol solution, followed by heating. UV spectra were obtained on a UV 210A Shimadzu spectrometer (Shimadzu, Kyoto, Japan). IR spectra were recorded on a Shimadzu IR-450 spectrometer as $\mathrm{KBr}$ pellets. ${ }^{1} \mathrm{H}-$ and ${ }^{13} \mathrm{C}-\mathrm{NMR}$, HSQC and HMBC spectra were recorded with Bruker AM-400 and DRX-500 spectrometers operating at 500 and $400 \mathrm{MHz}$ for ${ }^{1} \mathrm{H}$, and 125 and $100 \mathrm{MHz}$ for ${ }^{13} \mathrm{C}$, respectively. FABMS and HRFABMS were recorded on an AutoSpec 3000 spectrometer (VG, Manchester, UK) with glycerol as the matrix.

\subsection{Plant Material}

The aerial parts of E. rugulosa were collected from Yunnan Province, China. The voucher specimen (No. 0215159) was deposited in the KUN Herbarium of Kunming Institute of Botany, Chinese Academy of Sciences.

\subsection{Extraction and Isolation}

Dried plant material (400 g) of E. rugulosa was refluxed four times with ethanol (4.0 L) for $3 \mathrm{~h}$. After removal of the organic solvent under reduced pressure, the aqueous solution afforded precipitates, which were removed by filtration, and the filtrate was partitioned with ethyl ether to yield ethyl ether and aqueous fractions. The aqueous fraction was concentrated to a small volume (120 $\mathrm{mL})$ and applied to a Dianion HP 2MGL column, eluting with $\mathrm{H}_{2} \mathrm{O}-\mathrm{MeOH}(1: 0-0: 1)$ to afford five fractions (fr. 1-5). Fr. $2(0.4 \mathrm{~g})$ was subjected to $\mathrm{CC}$ on silica gel $\left(\mathrm{CHCl}_{3}-\mathrm{MeOH}-\mathrm{H}_{2} \mathrm{O}, 9: 1: 0.1-7: 3: 0.5\right)$, Sephadex LH-20 and MCI-gel CHP-20P, eluting with $\mathrm{H}_{2} \mathrm{O}-\mathrm{MeOH}$ (1:0-0:1) to afford compounds 2 (6 $\mathrm{mg})$ and $5(15 \mathrm{mg})$. Fr. $3(1.7 \mathrm{~g})$ was subjected to $\mathrm{CC}$ on silica gel $\left(\mathrm{CHCl}_{3}-\mathrm{MeOH}-\mathrm{H}_{2} \mathrm{O}, 9: 1: 0.1-\right.$ 7:3:0.5), Sephadex LH-20 $\left(\mathrm{H}_{2} \mathrm{O}-\mathrm{MeOH}, 1: 0-0: 1\right)$ and MCI-gel CHP-20P $\left(\mathrm{H}_{2} \mathrm{O}-\mathrm{MeOH}, 1: 0-0: 1\right)$ to afford 1 (8 mg), 3 (34 mg), 4 (59 mg) and $11(16 \mathrm{mg})$. Repeated CC on Sephadex LH-20 and MCI-gel CHP-20P, eluting with $\mathrm{H}_{2} \mathrm{O}-\mathrm{MeOH}$ (1:0-0:1), respectively, gave 7 (9 mg), 8 (10 mg) and 9 (50 mg) from Fr. 4 (1.7 g), and 6 (22 mg) and $10(24 \mathrm{mg})$ from Fr. 5 (0.7 g).

Compound 1: Yellow amorphous powder. UV-Visible $\lambda_{\max }(\mathrm{nm}) \mathrm{MeOH}: 265,296,331$; IR $\left(\mathrm{KBr}, \mathrm{cm}^{-1}\right)$ : 3.376, 1.640, 1.613, 1.508, 1.055, 780, 770; ${ }^{1} \mathrm{H}$ NMR (500 MHz, DMSO-d 6 ): 7.94 (d, J=8.6 Hz, H2', H6'), 6.92 (d, $J=8.6 \mathrm{~Hz}, \mathrm{H} 3$ ', H5'), 6.86 (s, H3), 6.82 (d, $J=1.6 \mathrm{~Hz}, \mathrm{H} 8), 6.43$ (d, J = 1.6 Hz, H6), 5.42 (d, $J=3.7$ Hz, H1"), 5.10 (d, $J=3.9,12.5 \mathrm{~Hz}, \mathrm{Ha} 6 "), 5.05$ (dd, $J=3.9,12.5 \mathrm{~Hz}, \mathrm{Hb6}$ "), 4.63 (m, H2"), 3.71 (m, H4"), 3.17-3.58 (m, H3", H5") ppm; ${ }^{13}$ C-NMR (125 MHz, DMSO-d 6 ): 181.9 (s, C-4), 162.9 (s, C-2), 161.4 (s, C-5), 161.1 (s, C-4'), 156.9 (s, C-9), 128.6 (d, C-2', C-6'), 121.0 (s, C-1'), 
116.0 (d, C-3', 5'), 105.4 (s, C-10), 103.1 (d, C-3), 99.9 (d, C-1"), 99.5 (d, C-6), 94.8 (d, C-8), 77.2 (d, C-3"), 76.3 (d, C-5"), 73.1 (d, C-2"), 69.5 (d, C-4"), 60.6 (t, C-6"); HR-FAB-MS (neg.): 431.1280 [M$\mathrm{H}^{-}$(calcd. for $\mathrm{C}_{21} \mathrm{H}_{19} \mathrm{O}_{10} 431.1102$ ).

Compound 2: Yellow amorphous powder. UV-Visible $\lambda_{\max }(\mathrm{nm}) \mathrm{MeOH}: 256,267,346$; IR (KBr, $\mathrm{cm}^{-}$ $\left.{ }^{1}\right): 3,450,2,920,1,650,1,573,1,515,990-600 ;{ }^{1} \mathrm{H}-\mathrm{NMR}\left(500 \mathrm{MHz}, \mathrm{MeOH}+\mathrm{DMSO}-\mathrm{d}_{6}\right): 7.40(\mathrm{~d}, J=$ $1.9 \mathrm{~Hz}, \mathrm{H} 2 '), 6.95$ (d, $J=1.9 \mathrm{~Hz}, \mathrm{H} 6 '), 6.78$ (s, H3), 6.61 (d, $J=1.8 \mathrm{~Hz}, \mathrm{H} 6), 6.48$ (d, $J=1.8 \mathrm{~Hz}, \mathrm{H} 8$ ), 5.16 (br t, $J=6.7$ Hz, H2"'), 5.08 (d, $J=8.1$ Hz, H1"), 3.78-4.40 (m, H2", H3", H4", H5"), 3.62 (m, H1"'), 1.68 (s, H5"'), 1.62 (s, H4"') ppm; ${ }^{13} \mathrm{C}-\mathrm{NMR}$ (125 MHz, MeOH+DMSO-d 6 ): 183.7 (s, C-4), 166.7 (s, C-7), 162.1 (s, C-5), 158.9 (s, C-9), 151.1 (s, C-4'), 147.3 (s, C-3'), 130.1 (s, C-3"'), 123.7 (s, C-1'), 127.1 (s, C-5'), 122.1 (s, C-2"'), 117.6 (d, C-6'), 114.6 (d, C-2'), 107.1 (s, C-10), 104.5 (s, C-3), 101.9 (d, C-1"), 101.0 (d, C-6), 96.1 (d, C-8), 78.5 (d, C-3"), 77.9 (d, C-5"), 74.7 (d, C-2"), 71.2 (d, C4"), 62.9 (t, C-6"), 28.4 (t, C-1"'), 25.6 (q, C-5"'), 17.8 (q, C-4"'); HR-FAB-MS (neg.): 515.1913 [M-H]' (calcd for $\mathrm{C}_{26} \mathrm{H}_{27} \mathrm{O}_{11}$ 515. 1657).

\subsection{Enzymatic hydrolysis of compounds $\mathbf{1}$ and $\mathbf{2}$}

An aqueous solution of 1 ( $3 \mathrm{mg})$ and maltase $(1 \mathrm{mg})$ was incubated at $37^{\circ} \mathrm{C}$ for $80 \mathrm{~h}$. The solution was extracted with $\mathrm{CHCl}_{3}$ and aglycone produced was identified as apigenin by comparison with compound 6 on silica gel TLC using $\mathrm{CHCl}_{3}-\mathrm{MeOH}-\mathrm{H}_{2} \mathrm{O}(8: 2: 0.2), R_{f}=0.68$. The aqueous layer was concentrated to a residue, which was dissolved by water and examined for identification of the component sugar, and D-glucose was identified by direct comparison on silica gel TLC with an authentic sample, using $\mathrm{CHCl}_{3}-\mathrm{MeOH}-\mathrm{H}_{2} \mathrm{O}$ (7:3:0.5). $R_{f}=0.23$.

A solution of $2(2 \mathrm{mg})$ in $\mathrm{H}_{2} \mathrm{O}(1 \mathrm{~mL})$ were treated with crude cellulase $(7 \mathrm{mg})$ at $37{ }^{\circ} \mathrm{C}$ for $60 \mathrm{~h}$. The reaction mixture was diluted with $\mathrm{H}_{2} \mathrm{O}(2 \mathrm{~mL})$, and extracted with $\mathrm{CHCl}_{3}(3 \mathrm{~mL} \times 2)$. The aqueous layer was concentrated to a residue, which was dissolved by water and examined for identification of the component sugar, and D-glucose was identified by direct comparison on silica gel TLC with an authentic sample, using $\mathrm{CHCl}_{3}-\mathrm{MeOH}-\mathrm{H}_{2} \mathrm{O}(7: 3: 0.5) . R_{f}=0.23$.

\section{Conclusions}

A detailed phytochemical investigation on E. rugulosa led to the isolation of two new flavonoid glycosides, apigenin 4'-O- $\alpha$-D-glucopyranoside (1) and 5,7,3',4'-tetrahydroxy-5'-C-prenylflavone-7-O$\beta$-D-glucopyranoside (2), together with nine known compounds (3-11). Among them, compounds 7-10 were isolated for the first time from E. rugulosa.

\section{Acknowledgements}

The authors are grateful to the staffs of the analytical group at State Key Laboratory of Phytochemistry and Plant Resources in West China, Kunming Institute of Botany, Chinese Academy of Sciences, for measuring the spectral data. 


\section{References and Notes}

1. Wu, C.Y. Flora of China; Science Press: Beijing, China, 1988; Vol. 66, p. 308.

2. Jiangshu New College of Medicine. The Dictionary of Chinese Medicine; Shanghai Press of Science and Technology: Shanghai, China, 1985; p. 2132.

3. Liu, A.L.; Liu, B.; Qin, H.L.; Lee, S.M.; Wang, Y.T.; Du, G.H. Anti-influenza virus activities of flavonoids from the medicinal plant Elsholtzia rugulosa. Planta Med. 2008, 74, 847-850.

4. Li, H.Z.; Nakashima, T.; Tanaka, T.; Zhang, Y.J.; Yang, C.R. Two new maltol glycosides and cyanogenic glycosides from Elsholtzia rugulosa Hemsl. J. Nat. Med. 2008, 62, 75-79.

5. He, Z.D.; Liu, Y.Q.; Yang, C.R. Glycosides from Ligustrum purpurascens. Acta Bot. Yunnanica 1992, 14, 328-336.

6. Ouyang, M.A.; Wang, H.Q.; Liu, Y.Q.; Yang, C.R. Triterpenoid saponins from the leaves of Ilex latifolia. Phytochemistry 1997, 45, 1501-1506.

7. She, G.M.; Wang, D.; Zeng, S.F.; Zhang, Y.J.; Chang, C.R. New antioxidative phenylethanoids and sugar esters from Ku-Ding tea (the leaves of Ligustrum purpurascens). J. Food Sci. 2008, 73, 476-482.

8. Chen, H.Y.; Zhou, C.X.; Lou, Y.J.; Duan, Z.H.; Zhao, Y. Chemical constituents from Elsholtzia blanda. Zhongguo Zhong Yao Za Zhi 2005, 30, 1589-1591.

9. Ma, J.Y.; Wang, Z.T.; Xu, L.S.; Xu, G.J. A sesquiterpene lactone glucoside from Ixeris denticulata f. pinnatipartita. Phytochemistry 1999, 50, 113-115.

10. Shen, C.C.; Chang, Y.S.; Ho, L.K. Nuclear magnetic resonance studies of 5, 7-dihydroxy flavonoids. Phytochemistry 1993, 34, 843-845.

11. Jiang, L.; Yao, Q.Q.; Xie, Y.Y. Study on chemical constituents of Sonchus arvensis L. Food Drug 2009, 11, 27-29.

12. Zhang, R.L.; Sun, X.C.; Li, W.X.; Wu, L.J.; Huang, J.; Sun, B.H. Isolation and identification of chemical constituents of Polygonum perfoliatum L. J. Shenyang Pharm. Univ. 2008, 25, 105-107.

13. Zhou, Z.H.; Yang, C.R. Chemical constituents of crude green tea, the material of Pu-er tea in Yunnan. Acta Bot. Yunnanica 2000, 22, 343-350.

14. Yang, L.; Che, Q.M.; Bi, C.; Sun, Q.S. Flavonoid compounds in solid wastes of Radix Glycyrrhizae. Chin. Tradit. Herb. Drugs. 2007, 38, 671-673.

15. Zhao, Y.; Lin, Q.C.; Zhao, Y.; Chen, Y.G. Studies on the constituents from the herb of Elshotzia rugulosa. Zhongguo Zhong Yao Za Zhi 2004, 29, 1144-1146.

16. Wang, X.K. Natural Medicinal Chemistry; People's Medical Publishing House: Beijing, China, 1988; p. 218.

17. Mathela, D.K.; Pant, A.K.; Mathela, C.S. A pyrone glycoside from Erigeron karwinskyanus. Phytochemistry 1984, 23, 2090.

18. Gao, Y.M.; Wang, M.Z.; Wang, J.P.; Zhao, Q.; Qin, H.Y.; Mu, H J.; Guan, G.J. Chemical constituents from Lonicera japonica. Chin. Tradit. Herb. Drugs. 1995, 26, 568-569.

19. Markham, K.R.; Ternai, B.; Stanly, R.; Geiger, H.; Mabry, T.J. ${ }^{13}$ C-NMR studies of flavonoidsIII. Tetrahedron 1978, 34, 1389-1397. 
20. Bohlmann F.; Abraham, W.R. Neus Prenylflavone aus Helichrysum hypocephalum. Phytochemistry 1979, 18, 1851-1853.

Sample Availability: Samples of the compounds are available from the authors.

(C) 2009 by the authors; licensee Molecular Diversity Preservation International, Basel, Switzerland. This article is an open-access article distributed under the terms and conditions of the Creative Commons Attribution license (http://creativecommons.org/licenses/by/3.0/). 